\title{
FORMATION OF LEADERSHIP QUALITIES IN STUDENTS
}

(C) 2016

I.V. Nikulina, candidate of pedagogical sciences, associate professor of Theory and Methods of Professional Education Department

Samara National Research University, Samara (Russia)

Abstract. The following paper discusses the features of leadership in a student group. The author presents interpretations of leadership phenomenon that exist in domestic and foreign literature and analyzes the phenomenon of leadership differentiation role in a group. A phenomenon of leadership identification, as a mechanism of the leader influence on followers, is studied by the experimental method. As a result the author comes to the conclusion that the identification of the group takes place mainly with an instrumental or emotional leader, as a great number of identity attributes are ascribed to him/her. A self-perceptual questionnaire helps to study a social-perceptual mechanism of identification process deployment in leadership. The experimental results show that the formation of leadership qualities in students is necessary to consider the features of role differentiation in a group: the instrumental leader organizes a student group for the solution of educational and professional problems; the emotional leader takes care of favorable psychological climate maintenance in a group, strengthens the group cohesion.

Keywords: leadership; leader; leadership roles; leadership skills; teacher; student; student group; formation of leadership qualities; role differentiation of leadership; emotional leader; instrumental leader; identification; identification of quality.

УдК $37.034+378$

\section{НРАВСТВЕННОЕ ВОСПИТАНИЕ СТУДЕНТОВ В КУЛЬТУРНО-ОБРАЗОВАТЕЛЬНОМ ПРОСТРАНСТВЕ ВУЗА}

(C) 2016

С.В. Пупков, доктор педагогических наук, доцент, профессор кафедры социологии

Рязанский государственный университет имени С.А. Есенина, Рязань (Россия)

Аннотащия. В статье аргументируется необходимость осуществления нравственного воспитания студентов вуза как приобщения обучающихся к ценностям, находящимся в создаваемом преподавателем культурнообразовательном пространстве. Дополнено научное представление о понятии «образовательное пространство» и доказано, что содержательное наполнение понятие «культурно-образовательное пространство» получает через привлечение термина «культурный». Выявлена сущность культурно-образовательного пространства вуза, заключающаяся в его многомерности, которая выражается в бесконечности транслируемой через каналы образования и воспитания культуры как опыта деятельности, опыта духовно-практического освоения мира в морали, опыта нравственных, ценностных отношений по критерию предельного его (опыта) основания (ценность человека), благодаря которому субъект-объектные, объектно-субъектные и субъект-субъектные отношения становятся дополнительными. Раскрыто содержание культурно-образовательного пространства, образуемого субъект-объектными и субъект-субъектными отношениями, связь между которыми становится диалектической за счет объектно-субъектных отношений, в которых возникают ценности, являющиеся аксиологическим ядром деятельности, аксиологической формой культуры. Определено предназначение субъект-объектных и субъектсубъектных отношений как образующих содержание культурно-образовательного пространства и исходя из такого предназначения выявлены функции педагогической деятельности преподавателя, осуществляющего нравственное воспитание студентов: обеспечение хранения, воспроизводства, трансляции культуры как опыта деятельности, заключенного (опыта) в остенсивных, императивных, аксиологических формах культуры, ее формах-принципах; организация работы студентов с культурными формами; организация восхождения студента от аксиологических форм культуры к ее формам-принципам; передача опыта духовно-практического освоения мира в морали, опыта поведения и деятельности, опыта нравственных, ценностных отношений.

Ключевые слова: студент; преподаватель; вуз; воспитание; нравственное воспитание; пространство; культурно-образовательное пространство; ценность; отношение; субъект-объектные отношения; объектносубъектные отношения; субъект-субъектные отношения; сущность; содержание; функция.

Современный вуз функционирует в условиях социально-экономических перемен, происходящих в нашем обществе, затрагивающих все сферы его материальной и духовной жизни, влияющих на субъективную ценностную систему студентов. Одним из ведущих ориентиров развития общества становится жизнь, достойная человека. Однако сегодня идет размывание представлений о норме: все дозволено, каждый прав по-своему, что оборачивается оправданием любого порока. [1, с. 79]. «Если "все дозволено", подчеркивает В.Н. Сагатовский, - если главное - это наслаждение новизной, если нет ответственности и целое надо разрушать, а не развивать, сохраняя, то процессы социализации и индивидуализации имеют все шансы смениться процессом тотального развращения» $[1$, с. 83$]$. Выход из этой ситуации должен быть найден. Одним из возможных вариантов выхода является нравственное воспитание студентов вуза через их приобщение к ценностям, через организацию ценностно-ориентационной деятельности, являющейся способом осуществления ценностей, через развитие способности к морально-этической рефлексии, 
являющейся механизмом морального, ценностного выбора.

В настоящее время стало очевидно, что без сохранения нравственных ценностей, норм под знаком пересмотра их содержания, обусловленного (пересмотра) социально-экономическими, политическими изменениями в обществе, не удастся создать условия для жизни, достойной человека. Мир ценностей есть мораль, пространство которой есть пространство отношений между людьми.

В практике образования подобное понимание морали, пространство которой есть конкретные, строящиеся для конкретных целей отношения между людьми, должно составить основу для целенаправленного нравственного воспитания студента. Нравственное воспитание студента осуществляется в процессе образования, цели и смысл которого становятся понятными в зависимости от того, к каким ценностям приобщаются студенты. Становление студента как человека нравственного происходит в процессе освоения им системы ценностей, функциями которых, как подчеркивает Б.С. Братусь, являются функция создания образа, эскиза будущего, той перспективы развития личности, которая не вытекает прямо из наличия сегодняшней ситуации, и функция оценки [2, с. 31-32].

Заметим, что в трактовке понятия «воспитание» мы придерживаемся точки зрения А.В. Бездухова и Ю.В. Лопуховой, утверждающих, что воспитание есть приобщение человека к ценностям [3, с. 69].

Ценности студента, находящие свое выражение в образе человека нравственного, приходят к нему из создаваемого преподавателем вуза культурно-образовательного пространства. Из этого пространства студент черпает ценности, регулирующие и направляющие его деятельность и взаимодействие с людьми. В то же время студент, говоря словами Гегеля, «ставит себе цели из себя и черпает из себя материал своих действий» [4, с. 131], материал для собственного нравственного развития.

В создаваемом преподавателем вуза культурнообразовательном пространстве «проживают» не только студент, но и педагог, принимающие или отклоняющие ценности другого. Такое пространство, представляя собой единство опыта ценностно-ориентационной деятельности и опыта ценностных отношений студентов к миру, к людям и к себе, опыта нравственной деятельности и опыта нравственных отношений, необходимо как для воспроизведения, трансляции общечеловеческого опыта, так и для совершенствования, созидания этого опыта.

Обоснование деятельности преподавателя вуза, ориентированного на создание условий для того, чтобы студент «черпал» цели собственного нравственного развития «из себя», на нравственное воспитание студентов, связано с раскрытием сущности и содержания культурно-образовательного пространства.

Решение задачи обоснования сущности и содержания понятия «культурно-образовательное пространство» требует раскрытия содержания понятия «пространство».

Наша задача облегчается тем, что достаточно всесторонний научный анализ понятия «пространство» выполнен Л.В. Вершининой [5], которая осмыслила термины «образовательный», «воспитательный», «пе- дагогический» в сочетании с понятием «пространство», обосновала содержание понятия «пространство». Несмотря на это, мы считаем необходимым обратиться к проблеме культурно-образовательного пространства, поскольку, как показывает анализ научной литературы, ученые преимущественно раскрывают содержание и структуру понятий «образовательное пространство» (С.К. Бондырева [6], Е.В. Волкова [7], М.В. Семина [8]), «воспитательное пространство» (И.Д. Демакова [9], Н.Л. Селиванова [10], И.В. Плаксина [11], М.В. Рыбакова [12], М.В. Шакурова [13]), «аксиологическое педагогическое пространство» (Л.В. Вершинина [5]).

Заметим, что общим во взглядах ученых при имеющихся у них различиях относительно подходов к созданию воспитательного, образовательного пространства, характеристик образовательного пространства, структуры воспитательного пространства является то, что системообразующим компонентом пространства считаются отношения, в которые педагог вовлекает учащихся, студентов, организуя их деятельность и общение, а само пространство признается создаваемым педагогами.

Суть такого общего заключена в идеях С.К. Бондыревой и Н.Л. Селивановой. Согласно С.К. Бондыревой, единое образовательное пространство как особый социально-психологический и социокультурный феномен есть система «многоплановых и многомерных отношений, объективно воспроизводящихся и самостоятельно развивающихся в новой исторической среде в процессе организации и трансляции определенной, необходимой в современном изменяющемся обществе совокупности знаний, функционирующей в реальном пространственно-временном континууме, включающем в качестве субъектов действия страны СНГ, и отличающейся высокой коммуникативной способностью, устойчивостью и стабильностью» [6, с. 27-28]. Ведущей идеей осуществленного Н.Л. Селивановой анализа понятия «воспитательное пространство» является то, что «воспитательное пространство - результат деятельности, причем не только созидательной, но и интегрирующей <...> среду надо уметь использовать в воспитательных целях, а воспитательное пространство надо уметь создавать» [10, c. 255]. Такое общее и становится отправным моментом для обоснования содержания понятия «культурно-образовательное пространство».

Для обоснования сущности и содержания понятия «культурно-образовательное пространство» важными, на наш взгляд, являются научные представления о воспитании студентов как приобщении к ценностям [3, с. 69], которые становятся мотивами отношений студентов к окружающим людям и к себе.

В нашей статье мы, опираясь на результаты науковедческого анализа понятия «пространство», сделанного Л.В. Вершининой, конкретизируем положения ученого о данном понятии, акцентируя внимание на том, что осталось вне поля зрения ученого.

Отправным моментом для осмысления Л.В. Вершининой понятия «пространство» является понимание данного явления в философии, где оно трактуется «как взаимное расположение сосуществующих объектов» $[14$, с. 468$]$. Соглашаясь с Л.В. Вершининой в том, что главной стороной любого пространства яв- 
ляются отношения, а сами отношения есть конкретные отношения между объектами, между субъектом и объектом [5, с. 84], заметим, что вне поля зрения ученого остались не собственно отношения, которые являются системообразующим компонентом воспитательного пространства, образовательного пространства, аксиологического педагогического пространства, а такие типы отношений как «субъект-субъектные отношения», «субъект-объектные отношения» и «объектно-субъектные отношения».

С субъект-субъектными отношениями в целом все очевидно. Мы написали «в целом все очевидно», поскольку существуют разночтения в трактовке данных отношений в их соотнесении с субъект-объектными отношениями.

Так, согласно О.С. Газману [15], И.А. Колесниковой [16], Н.Б. Крыловой [17] и другим ученым, в рамках гуманистической педагогики речь должна идти главным образом о субъектах образования, воспитания и обучения.

Мы согласны с тем, что в гуманистической парадигме образования действуют субъекты. В этом ее главное отличие от традиционной парадигмы, в которой учащийся предстает как объект воздействия, а процесс обучения, например, представляет собой «легко просматриваемый, последовательный и контролируемый порядок, с четко заявленными стадиями и их результатами» [18, с. 107].

Несмотря на это, и в гуманистической парадигме следует признавать наличие объекта. Следует различать те системы отношений, в которых находятся и преподаватель, и студент. Такие отношения не могут быть только субъект-субъектными. В этой связи В.В. Краевский подчеркивает, что человек, которого мы обучаем и воспитываем, в одном определенном отношении выступает как объект. В то же время он, конечно, и субъект. Однако он выступает как субъект в иной системе отношений, например, становится субъектом собственной познавательной деятельности. Педагогическое же воздействие остается за педагогом. Педагог осуществляет педагогическое руководство. Субъект-субъектное отношение существует внутри субъект-объектного, им определяется, им стимулируется [19, с. 34-37].

Другими словами, студент, прежде чем стать субъектом деятельности, субъектом морального и ценностного выбора, должен вначале побыть в роли объекта, что не противоречит идеям гуманистической парадигмы образования. Речь идет в данном случае о педагогическом влиянии, о педагогическом руководстве, осуществляемым в контексте именно гуманистической, а не традиционной парадигмы образования.

Осуществляя нравственное воспитание студента, преподаватель вуза воздействует на его смысловую сферу сознания, которая, по утверждению А.Г. Асмолова, является психологическим объектом воспитания: «Психологическим объектом воспитания являются смысловые образования личности» [20, с. 117]. Смысловые образования, как подчеркивает Б.С. Братусь, будучи основными конституирующими (образующими) единицами личности, непосредственно определяют главные и относительно постоянные отношения человека к миру, к людям и к себе [2, с. 26], мотивами которых являются ценности.
Чтобы студент осваивал транслируемые ему преподавателем вуза ценности, необходимо создавать предпосылочное состояние. Ценности вначале предстают перед студентом в объективной ценностной системе, в «объективно-реальной действительности» $[21$, с. 45]. Когда ценности освоены студентом, они, став достоянием его личности, помещаются «в потаенный план сознания», начинают определять его субъективную ценностную систему.

Предпосылочное состояние создается в результате формирования, оформляющего, как подчеркивает В.П. Бездухов, достигнутый в определенный период обучения и воспитания на конкретном этапе подготовки студентов к профессиональной деятельности, уровень личностного развития (уровень развития смысловой сферыл. - С.П.), уровень знаний, опыта деятельности и системы отношений (нравственных, ценностных) к миру, к людям и самому себе [22, c. $47-48]$.

Что касается объектно-субъектных отношений, то это уже не столько область педагогического руководства, педагогического влияния, сколько область, указывающая на то, каким образом ценность предстает перед человеком. А это есть область этической науки, точнее, аксиологии как учения о ценностях, которые, согласно М.С. Кагану, есть отношения к... [23, с. 69] и которые, согласно Б.С. Братусю, есть осознанные общие смысловые образования, являющиеся, повторим еще раз, объектом психологической науки.

М.С. Каган аргументированно обосновывает, что ценность есть отношение, причем диспозиционное отношение, поскольку «объект» и «субъект» - не «вещи», а позиция «вещей» [23, с. 67]. «Ценность, пишет М.С. Каган, - предстает перед нами именно как отношение. Причем специфическое отношение, поскольку она связывает объект не с другим объектом, а с субъектом, то есть носителем социальных и культурных качеств, которые и определяют сверхиндивидуальное содержание его духовной деятельности; деятельность человека и является реальным отношением, в котором он выступает как субъект, хотя в другой ситуации он окажется объектом для другого субъекта $<\ldots>$ Ценность и возникает в объектносубъектном отношении» [23, с. 67].

Такое понимание М.С. Каганом процесса возникновения ценностей, во-первых, не противоречит идеям О.Г. Дробницкого о том, что ценность объективна. Ученый установил, что ценность - это свойство общественного предмета, в котором уже заключен человек. Ценность предмета зависит от законов социального движения, и в этом смысле она принадлежит предмету объективно. Ценность объективна [24, с. 328]. Во-вторых, вписывается в идеи В. Брожика об освоении ценностей. Студента вначале информируют о ценностях, предъявляют ему ценности (ценность в потенции), находящиеся в объективной ценностной системе общества. Отношение студента к объекту связывает его уже не с объектом, а с субъектом, точнее с субъектом деятельности, в которой реализуется адекватная содержанию деятельности позиция. Освоение ценности, как подчеркивает В. Брожик, связано с еe опредмечиванием. Однако, если ценность как опредмечивание является отправным пунктом для ее освоения, то ценность как освоение является уже ре- 
зультатом процесса ее возникновения [21, с. 41]. Осваивать можно только то, что есть в объективной реальности. В этой реальности находятся и ценности, предстающие как значения объекта для субъекта, каким является студент, преподаватель вуза.

Объекты, предметы, как подчеркивает М.С. Каган, становятся носителями ценностей, а человек оценивает данные объекты, предметы, выявляя тем самым их значение (благо, добро, справедливость и т.д.) для себя $[23$, с. 68$]$.

Выполненный нами анализ субъект-объектных, субъект-субъектных и объектно-субъектных отношений позволяет дополнить научное представление о понятии «образовательное пространство». Суть такого дополнения заключается в том, что системообразующим компонентом образовательного пространства являются не просто отношения, в которые преподаватель включает студентов с целью освоения ими системы ценностей, но субъект-объектные отношения, внутри которых находятся субъект-субъектные, и объектно-субъектные отношения. Содержание образовательного пространства образуют субъект-объектные отношения, внутри которых находятся субъектсубъектные, и объектно-субъектные отношения, находящиеся в диалектической связи. Суть такой связи заключается в том, что, если ценности возникают в объектно-субъектном отношении, то предстают они вначале в субъект-объектном отношении (формирование), а осваиваются в субъектных-субъектных отношениях (воспитание, образование). Однако такое понимание связи отношений, образующих содержание образовательного пространства, еще не дает целостного представления о том, как студент осваивает ценности. Простого выявления таких отношений в качестве образующих содержания образовательного пространства явно не достаточно, поскольку при таком подходе к содержанию образовательного пространства за его рамками остаются собственно ценности.

Образовательное пространство создается преподавателем вуза, который как субъект деятельности через организацию познавательной деятельности студентов предъявляет (информирует, сообщает) им ценности с помощью разнообразных методов. Другими словами, преподаватель «помещает» между собой (субъектом) и студентом (объектом) ценности, которые, будучи объективными, возникают в объектно-субъектном отношении. Это означает, что внутри субъект-объектных отношений в процессе образования возникают особые отношения, в которых «вычленяется их внутренний, не сводимый к практическому смысл, который становится мотивом» [25, с. 101] освоения студентом ценностей. Такими особыми отношениями являются объектно-субъектные отношения, где объектом являются предметы, явления, факты и т.д. а субъектом - студент (преподаватель и т.д.), наделяющий смыслом значения предметов, явлений, фактов и т.д. Наделение смыслом значения предмета осуществляется в организуемой преподавателем ценностноориентационной деятельности студента, которая как духовная деятельность делает созвучными различные ценностные миры. Данная деятельность является способом осуществления ценностей как преподавателем, так и студентом. Через эту деятельность осуществля- ется «движение» ценностей от одного субъекта к другому, благодаря чему происходит обогащение не только субъективной ценностной системы каждого, но и обогащение собственно субъект-субъектных отношений, возникающих, подчеркнем еще раз, внутри субъект-объектных отношений. При этом субъектсубъектные отношения выводят и преподавателя, и студента на новый виток духовно-практического освоения мира в морали. В обогащенных субъектсубъектных отношениях возникает новая педагогическая реальность, а в совместной ценностно-ориентационной деятельности создается «новое» образовательное пространство. «Новое» в смысле обогащенное ценностными значениями. Субъект-субъектные отношения отражают воспитание, которое есть не что иное как приобщение студента к ценностям.

Свое содержательное наполнение культурнообразовательное пространство получает через привлечение термина «культурный», что позволяет исследовать явление пространства в определенной предметной области - в области культуры, являющейся объектом изучения культурологии. При этом мы учитываем, что культурно-образовательное пространство создается деятельностью преподавателя вуза, которая есть определенный тип отношений человека к миру и к людям, к педагогической деятельности, к педагогической реальности, к ее субъектам.

Раскрытие явления культурно-образовательного пространства в особом методологическом ракурсе сквозь призму культуры - дает нам возможность обосновать сущность и содержание такого пространства.

Мы обосновываем сущность и содержание культурно-образовательного пространства, исходя из термина «культурный», хотя основную смысловую нагрузку в педагогическом исследовании несет термин «образовательный». Отметим, что если понятие «культурно-образовательное пространство» исследуется в рамках культурологии, то основную смысловую нагрузку в нем несет термин «культурный». Если в рамках педагогики, то термин «образовательный». При этом значение ни одного из данных терминов не преуменьшается.

Сущность и содержание культурно-образовательного пространства, создаваемого деятельностью преподавателя вуза, нам видится в наличии субъектобъектных отношений, внутри которых находятся субъект-субъектные и объектно-субъектные отношения, находящиеся между собой в диалектической связи. При обосновании сущности культурно-образовательного пространства мы исходим из того, что определить сущность данного пространства - значит выявить ведущую его характеристику. Такой ведущей характеристикой культурно-образовательного пространства является его многомерность.

Сущность культурно-образовательного пространства заключается в его многомерности, выражающейся в бесконечности транслируемой через каналы образования и воспитания культуры как опыта деятельности, опыта духовно-практического освоения мира в морали, опыта нравственных, ценностных отношений по критерию предельного его (опыта) основания (ценность человека), благодаря которому субъектобъектные, объектно-субъектные и субъект-субъект- 
ные отношения становятся дополнительными. Дополнительность данных отношений, обеспечиваемая организацией в рамках педагогической деятельности «движения» остенсивных, императивных, аксиологических форм и форм-принципов культуры (формы хранения и трансляции культуры как опыта $\rightarrow$ работа с культурными формами), способствует становлению студента как «личности-для-себя».

Содержание культурно-образовательного пространства образуют субъект-объектные и субъектсубъектные отношения, связь между которыми становится диалектической за счет объектно-субъектных отношений, в которых возникают ценности, являющиеся аксиологическим ядром деятельности, аксиологической формой культуры. Предназначением создаваемых деятельностью преподавателя вуза субъект-объектных отношений является воспроизводство, трансляция хранимого в остенсивных, императивных аксиологических формах и формах-принципах культуры опыта познавательной, ценностно-ориентационной. Исходя из такого предназначения субъектобъектных отношений как образующих содержания культурно-образовательного пространства, функциями педагогической деятельности преподавателя, осуществляющего нравственное воспитание студентов являются: 1) обеспечение хранения, воспроизводства, трансляции культуры как опыта деятельности, заключенного (опыта) в остенсивных, императивных, аксиологических формах культуры, ее формах-принципах; 2) организация работы студентов с культурными формами.

Предназначением субъект-субъектных отношений, возникающих внутри субъект-объектных отношений, является со-причастное выделение и осмысление субъектами культурных значений опыта познавательной, ценностно-ориентационной деятельности, приводящих (выделение и осмысление) к обогащению аксиологического ядра деятельности каждого субъекта. Благодаря такому обогащению происходит возвращение опыта деятельности, форм хранения культуры на витке личностной деятельности. Исходя из такого предназначения субъект-субъектных отношений как образующих содержания культурно-образовательного пространства, функциями педагогической деятельности преподавателя, осуществляющего нравственное воспитание студентов являются: 1) организация восхождения студента от аксиологических форм культуры к ее формам-принципам; 2) передача опыта духовно-практического освоения мира в морали, опыта поведения и деятельности, опыта нравственных, ценностных отношений.

Предназначение объектно-субъектных отношений в содержании культурно-образовательного пространства, в которых возникают ценности, не выявляется, поскольку они не существуют вне потребностей человека. Эти отношения находятся в иной плоскости существования. Они начинают существовать в случае появления потребности человека в чем-то. Своим возникновением любая ценность, в том числе и ценность человека, как предельное основание деятельности, обязана потребностям людей. Потребность преподавателя в студенте, студента в преподавателя их заинтересованное отношение друг к другу порождают и определенную систему нравственных, ценностных отношений. Объектно-субъектные отношения характеризуют не столько содержательный, сколько процессуальный аспект ценностно-ориентационной деятельности. Ценности начинают определять содержание этой деятельности уже после того, как они освоены, помещены «во внутренний план» сознания. В осознанных и принятых студентом ценностях, которые существуют и реализуются в ситуации выбора, воплощается нравственная личность студента на пути ее восхождения к культуре через каналы образования и воспитания. Культурно-образовательное пространство вуза при решении задачи нравственного воспитания студента начинает приобретать ценностную значимость тогда, когда его содержание реализуется в отношении к студенту, ради студента, во имя его развития и становления как субъекта культуры и морали.

\section{СПИСОК ЛИТЕРАТУРЫ:}

1. Сагатовский В.Н. Есть ли выход у человечества? СПб.: Петрополис, 2000. 148 с.

2. Братусь Б.С. Нравственное сознание личности (психологическое исследование). М.: Знание, 1985. $64 \mathrm{c}$.

3. Бездухов А.В., Лопухова Ю.В. Воспитание как движение, превращающее возможное в действительное // Известия РАО. 2010. № 1(17). С. 66-75.

4. Гегель Г. Энциклопедия философских наук: в 4 т. Т. 1. Наука логики. М.: Мысль, 1975. 452 с.

5. Вершинина Л.В. Аксиологическое пространство образования: ценностное сознание учителя. Самара: СГПУ, 2003. $150 \mathrm{c}$.

6. Бондырева С.К. Психолого-педагогические проблемы интегрирования образовательного пространства: избранные труды. М.: МПСИ; Воронеж: НПО «МОДЭК», 2003. 352 с.

7. Волкова Е.В. Пространство знаний и современное образовательное пространство // Мир психологии. 2012. № 4. C. 179-185.

8. Семина М.В. Образовательное пространство как системный феномен // В мире научных открытий. 2012. № 9.2 (33). С. 413-427.

9. Демакова И.Д. Деятельность педагога в воспитательном пространстве // Стратегии воспитания в образовательной системе России / под ред. И.А. Зимней. М.: Издательский сервис, 2005. С. 279-294.

10. Селиванова Н.Л. Воспитательная система и воспитательное пространство // Стратегии воспитания в образовательной системе России / под ред. И.А. Зимней. М.: Издательский сервис, 2005. С. 242-259.

11. Плаксина И.В. Типологические характеристики воспитательного пространство // Гуманитарные, социально-экономические и общественные науки. 2013. № 4. C. 413-417.

12. Рыбакова М.В. Воспитательное пространство: структурный аспект // Карельский научный журнал. 2013. № 4. C. 91-93.

13. Шакурова М.В. Воспитательное пространство: опыт структурирования // Вопросы воспитания. 2015. № 1. С. 62-68.

14. Философский словарь / под ред. И.Т. Фролова. М.: Республика, 2001. 719 с.

15. Газман О.С. От авторитарного образования к педагогике свободы // Новые ценности образования. Вып. 2. М.: Инноватор, 1995. С. 16-45. 
16. Колесникова И.А. О критериях гуманизации образования // Гуманизация образования. Теория. Практика. СПб, 1994. С. 37-45.

17. Крылова Н.Б. Культурология образования. М.: Народное образование, 2000. 272 с.

18. Киященко Л.П. Что сознание понимает в знании? // Что значит знать?: сборник научных статей. М.: Центр гуманитарных исследований, 1999. С. 100110.

19. Краевский В.В. Методология педагогического исследования. Самара: СГПИ, 1994. 165 с.

20. Асмолов А.Г. Культурно-историческая психология и конструирование миров. М: МПСИ; Воронеж: НПО «МОДЭК», 1996. 768 с.
21. Брожик В. Марксистская теория оценки / пер. со словац. М.: Прогресс, 1982. 264 с.

22. Бездухов В.П. Гуманизация образования в изменяющемся мире // Кулюткин Ю.Н., Бездухов В.П. Ценностные ориентиры и когнитивные структуры в деятельности учителя. Самара: СГПУ, 2002. С. 22-65.

23. Каган М.С. Философская теория ценности. СПб.: ТОО ТК «Петрополис», 1997. 205 с.

24. Дробницкий О.Г. Мир оживших предметов. М.: Политиздат, 1967. $351 \mathrm{c.}$

25. Бездухов В.П. Культура и образование // Кулюткин Ю.Н., Бездухов В.П. Ценностные ориентиры и когнитивные структуры в деятельности учителя. Самара: СГПУ, 2002. С. 66-173.

\section{MORAL EDUCATION OF STUDENTS IN THE CULTURAL AND EDUCATIONAL SPACE OF THE HIGH SCHOOL}

(C) 2016

S.V. Pupkov, doctor of pedagogical sciences, associate professor, professor of Sociology Department Ryazan State University named after S.A. Yesenin, Ryazan (Russia)

Abstract. The necessity of the moral education of students of high school students as an initiation to the values of which are in the teacher-written cultural and educational space. Amended scientific understanding of the concept of «educational space» and proved that the substantive content of the notion of «cultural and educational space » gets through the involvement of the term «culture». The essence of cultural and educational space of the university lies in its multi-dimensionality, which is expressed in infinity broadcast through the channels of education and training culture as the experience of, the experience of spiritual and practical development of the world in the moral experience moral, value relationships according to the criterion limit it (experience) of the base (value of a person), by which the subjectobject, object-subject and subject-subject relations are optional. The content of the cultural and educational space, formed the subject-object and subject-subject relationship, the relationship between them becomes dialectical by the object-subject relationship in which there are values that are axiological nucleus of activity, axiological form of culture. Determine the purpose of the subject-object and subject-subject relations as the content of the image of cultural and educational space, and on the basis of this mission revealed features of pedagogical activity of the teacher conducting the moral education of students: to provide storage, reproduction, broadcast culture as the experience of concluded (experience) in ostensive, imperative, axiological forms of culture, its forms-principles; organization of the work of students with cultural forms; student organization ascent from axiological forms of culture its forms-principles; transfer of experience of spiritual and practical development of morality in the world, the experience of behavior and activity, experience, moral, value relations.

Keywords: student; teacher; school; education; moral education; space; cultural and educational space; value; attitude; the subject-object relations; object-subject relations; subject-subject relationship; essence; content; function.

УДК 378

\section{ВЛИЯНИЕ СРЕДСТВ ИНОСТРАННОГО ЯЗЫКА НА ДИНАМИКУ ПРОФЕССИОНАЛЬНЫХ МОТИВОВ СТУДЕНТОВ}

(C) 2016

Т.И. Руднева, доктор педагогических наук, профессор, заведующий кафедрой теории и методики профессионального образования

А.Б. Храмцова, кандидат педагогических наук, доцент кафедры иностранных языков и профессиональной коммуникации Самарский наџиональный исследовательский университет имени академика С.П. Королёва, Самара (Россия)

Аннотащия. На основе проведенного мониторинга жизненных планов выпускников школ города Самары доказывается актуальность проблемы выбора вуза и профессии с целью приобретения профессиональных компетенций. В меняющихся условиях жизнедеятельности общества студентам необходимо приобрести регулятивные механизмы для успешного взаимодействия с представителями профессионального сообщества на международном уровне, что требует сформированности профессиональных мотивов. Результатами анкетирования студентов перового и второго курса доказывается, что совокупность образовательных средств при изучении иностранного языка способствует активизации не только познавательной деятельности студентов, но и усилению потребности в приобретении профессиональных компетенций, позволяющих интегрироваться в профессиональное сообщество. Таким образом, иностранный язык становится средством развития профессиональной мотивации и механизмом становления языковой личности, успешно социализирующейся в международном профессиональном пространстве. Методический аспект проблемы представляется условиями овладения ино- 